\title{
Effect of Submucosal Injection of Dexamethasone on Post-operative Sequelae of Third Molar Surgery
}

\author{
Deo $S P^{1}$, Shetty $\mathrm{P}^{2}$ \\ ${ }^{1}$ National Medical College and Teaching Hospital, Birgunj. ${ }^{2}$ Manipal College of Dental Science, Manglore, India.
}

\section{ABSTRACT}

Objective: This study was carried out to evaluate the effects of a single pre-operative sub-mucosal injection of dexamethasone after third molar surgery to see the effects on post-operative discomfort.

Methods: This study was a prospective, double-blind, randomized, clinical trial. The subjects were forty patients who underwent surgical removal of the mandibular impacted third molar under local anesthesia and after being randomly assigned to receive either an $8 \mathrm{mg}$ dexamethasone as submucosal injection or a normal saline injection into the lower buccal vestibule adjacent to the third molar. The maximum interincisal distance and facial contours were measured the baseline and post-surgically on Day 2 and 7. Post-operative pain was evaluated subjectively using a visual analog scale and objectively by counting the number of analgesic tablets used. All subjects were operated upon by the same investigator to minimize the difference from inter-operator variability.

Results: There was a significant difference in the measurements of the degree of swelling and trismus between the two groups on the $2^{\text {nd }}$ post-operative day. In contrast, there was no statistically significant difference between the groups on the $7^{\text {th }}$ post-operative day. The test group also used fewer analgesics post-operatively.

Conclusions: Submucosal injection of dexamethasone after third molar surgery is effective in reducing postoperative swelling and trismus. It also delays the onset of post-operative pain.

Keywords: dexamethasone, submucosal injection, third molar, third molar surgery, third molar extraction

\section{INTRODUCTION}

Third molar surgery (TMS) is probably traumatic and the most commonly performed dentoalveolar surgical procedure in oral-maxillofacial surgery clinics. As operators perform more invasive or difficult procedures, there will be an increased amount of trauma to the surgical site as well as the surrounding tissues. ${ }^{1}$ The inflammatory process is necessary if healing of traumatic tissue has to occur, but often excessive inflammations lead to unnecessary pain, trismus and swelling. The impact of these symptoms affect the quality of life in the days following surgery ${ }^{2}$.
Injured tissues immediately release local inflammatory mediators, like histamine, that produce vasodilatation leading to extravasations resulting in edema and sensitize the peripheral nocireceptors resulting in hyperalgesia ${ }^{3}$.Trismus is an inflammation of muscle of the mastication with edema preventing flexibility. Although these inflammatory mediators are released immediately after the trauma, these symptoms are not observed immediate after the surgery but rather begin gradually, peaking 1 - 3 days after the surgery ${ }^{4}$.

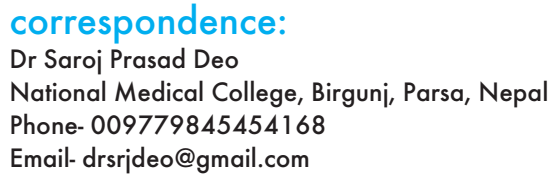

Email-drsrideo@gmail.com 
Traditionally, intravenous, intramuscular or oral CS have been advocated for lessening the severity of the above-mentioned symptoms by surgeons ${ }^{5,9}$. Despite the frequent clinical use of dexamethasone, there are not many reports in the literature stating the effectiveness of sub-mucosal injection of dexamethasone in reducing the post-operative discomfort following the TMS. Effectiveness of pre-operative submucosal dexamethasone remains poorly investigated in reducing the post-operative sequelae of $\mathrm{TMS}^{10,11}$.

\section{METHODS}

This prospective, randomized, control trial was carried out from March 2009 to October 2009 after obtaining approval from the institutional ethical committee. The inclusion criteria were subjects between 20 - 41 years of age who were in good general physical health with no clinically significant and relevant medical history (ASA I \& II ). Subjects having at least one partially or fully bony impacted mandibular third molar and who could understand and were willing to take part in the study and likely to comply with all study procedure were included in this study.

The exclusion criteria were subjects who were on antibiotics and or anti-inflammatory drugs within two weeks of the study entry, pregnant or lactating females and subjects with any active medical illness. Subjects were also excluded in whom the surgery lasted more than one hour and for whom the use of non-trial drugs were prescribed during study period.

The base line facial measurement was done by a 3 0 silk suture by using a modification of the method describe by Neupert at $\mathrm{al}^{12}$ and Schultze-Mosgau et al ${ }^{13}$.Five reference points were used angle of mandible, tragus, alar base, corner of the mouth and soft tissue pogonion. Three measurements were made: the distance from the tragus to the corner of mouth, the tragus to the pogonion and the mandibular angle to the ala of the nose (Figure 1). The pre-operative values of these measurements were considered as the baseline facial contour.

The subjects were asked to open the mouth slowly until pain was first felt. At that point, the distance between the incisors, edge of the maxillary and mandibular anterior teeth (IIO) were measured by a ruler ${ }^{14}$. The same method was used in the $2^{\text {nd }}$ and $7^{\text {th }}$ post-operative day.

The study subjects were randomly assigned into two groups: experimental (DXG) or control group (CTG). For randomization, a random-number table was used

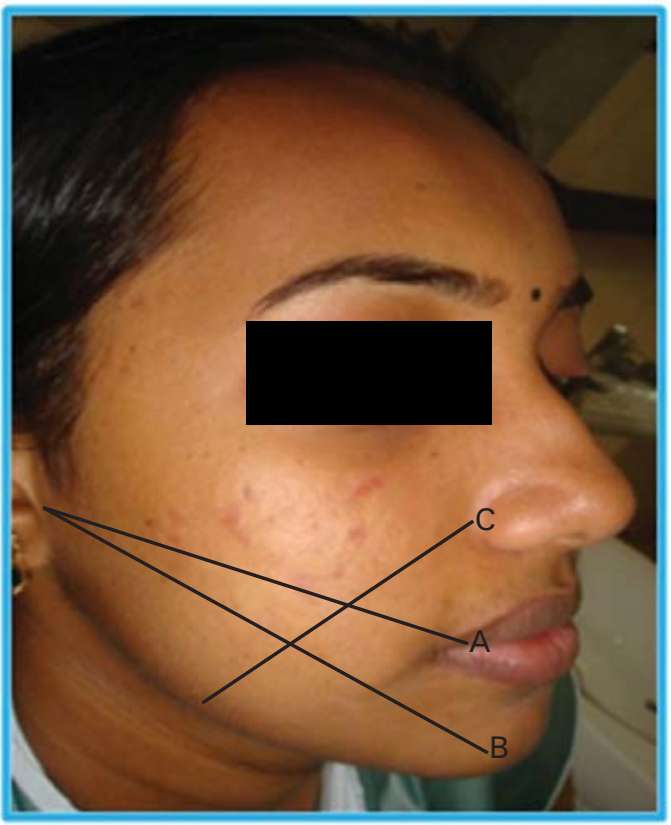

Figure 1. Showing measurements of facial contour (swelling) between the five references points: (A) tragus to corner of mouth, $(B)$ tragus to the pogonion and $(\mathrm{C})$ mandibular angle to ala of the nose

to generate a block randomization schedule chart specifying the group to which each subject would be assigned upon the first-come-first basis. Ampoules with normal saline (NS) and dexamethasone were given to the nurses who were supporting the trial. On the day of surgery, nurses prepared either the test drug (2 $\mathrm{ml}$ dexamethasone) or the placebo $(2 \mathrm{ml} \mathrm{NS})$ in identical $2 \mathrm{ml}$ syringes according to a random table and documented the same in a chart.

After the surgical preparation of the subjects, lignocaine $2 \%$ with epinephrine $1: 2,00,0000$ was used as the anesthetic agent to block the inferior alveolar, lingual and long buccal nerve. Dexamethasone $8 \mathrm{mg}(2 \mathrm{ml})$ or NS $2 \mathrm{ml}$ was injected submucosally into the perithird molar regions. All the subjects were operated by the same operator and under similar conditions to minimize operator variability. The surgical procedure was standardized by a 3-cornered flap followed by a buccal guttering and distal bone cutting with continuous irrigation with sterile NS. Post-operative instructions were given to subjects, including an ice pack for 20 minutes and a pressure pack for 30 minutes over the surgical site to achieve hemostasis. All the subjects were prescribed. Amoxicillin $500 \mathrm{mg}$ capsuler, per oral three times a day for 5 days and Ibuprofen $400 \mathrm{mg}$ tablets, per oral 8 hourly. The subjects were asked to take the first analgesic post-operatively as soon as the pain reached moderate level and asked to record the time. The subjects were instructed to not to take any other analgesic drugs. 
All the subjects were given a $10 \mathrm{~cm}$ visual analog scale (VAS) and instructed about the rating. ${ }^{15}$ They were asked to enter their pain level, the time at which the analgesic was taken, and the number of tablets taken until the end of the first post-operative week. They were asked to report to the OPD on the $2^{\text {nd }}$ and $7^{\text {th }}$ post-operative days. The maximum interincisal distance and facial contours were measured on these appointments by the same examiner who had assessed them pre-operatively. The technique and reference points used for these measurements were the same as those based in the pre-operative assessment. The evaluation of trismus and facial edema was recorded as the differences between pre-operative (baseline) and post-operative values.

All the demographic details, base line data and postoperative data were recorded in the case report form over the course of the study. All the data were entered into the spreadsheet (excel, Microsoft) and Chi-square test, Mann-Whitney $U$ test, $t$ student's paired and unpaired $t$ test, and fisher exact test were used for analysis of the data.

\section{RESULTS}

Forty subjects aged between 20 to 41 years were selected on the basis of inclusion and exclusion criteria. Twenty-four subjects were enrolled in the DXG group and 16 subjects in the CTG group. Ten subjects were excluded from the study. Three had an operating time exceeding an hour, two had been taking analgesics other than prescribed, three were lost for follow-up and two subjects did not complete the questionnaire properly. Data from 30 subjects were included in the study and analysed. The descriptive statistics, demographic and pre-operative variables are summarized in Tables 1 . Table 2 and 3 show the Mean and Standard Deviation (SD) of the absolute difference between post-operative (with $2^{\text {nd }}$ and $7^{\text {th }}$ day) and pre-operative measures, in relation with the groups.

\section{Swelling}

On the second postoperative day, although there was an average increase in facial swelling in both groups the Mann-Whitney $U$ test analysis showed a statistically very highly significant difference between the two groups $(P<0.001)$ (Table 2$)$.

On the seventh post-operative day, facial swelling in the DXG group was almost same as that of the CTG. There was no statistically significant difference between the two groups ( $P=0.088$ ) (Table 3 ). It was observed that facial contour by the seventh day post-operatively returned to normal in both the groups. (Figure 2)
Table1. Descriptive statistics for the demographic and operative variable

\begin{tabular}{|c|c|c|c|c|}
\hline & $\begin{array}{l}\text { Control } \\
\text { CTG } \\
\text { (n = 11) }\end{array}$ & $\begin{array}{l}\text { Dexamethasone } \\
\text { DXG } \\
\text { (n = 19) }\end{array}$ & $\begin{array}{l}\text { Total } \\
(\mathrm{n}=30)\end{array}$ & $\begin{array}{l}p \\
\text { value }\end{array}$ \\
\hline \multicolumn{5}{|l|}{ Gender } \\
\hline Male & $10(90 \%)$ & $8(42 \%)$ & $18(60 \%)$ & 0.018 \\
\hline Female & $1(9.1 \%)$ & $11(57.9 \%)$ & $12(40 \%)$ & \\
\hline \multicolumn{5}{|l|}{ Age } \\
\hline Average & $22.37 \mathrm{yrs}$ & 23.89 yrs & $24.93 \mathrm{yrs}$ & 0.648 \\
\hline \multicolumn{5}{|l|}{$\begin{array}{l}\text { Tobacco } \\
\text { use }\end{array}$} \\
\hline Yes & $4(36.4 \%)$ & $6(31.6 \%)$ & $10(33.3 \%)$ & 0.789 \\
\hline No & $7(63.6 \%)$ & $13(68.3 \%)$ & $20(66.7 \%)$ & \\
\hline \multicolumn{5}{|l|}{$\begin{array}{l}\text { Class of } \\
\text { impaction }\end{array}$} \\
\hline Class II & $9(81.8 \%)$ & $18(94.7 \%)$ & $27(90 \%)$ & 0.537 \\
\hline Class III & $2(12.2 \%)$ & $1(5.3 \%)$ & $3(10 \%)$ & \\
\hline \multicolumn{5}{|l|}{$\begin{array}{l}\text { Depth of } \\
\text { impaction }\end{array}$} \\
\hline Level A & $1(9.1 \%)$ & $5(26.3 \%)$ & $6(20 \%)$ & \\
\hline Level B & $8(72.7 \%)$ & $10(52.6 \%)$ & $18(60 \%)$ & 0.465 \\
\hline Level C & $2(18.2 \%)$ & $4(21.4 \%)$ & $6(20 \%)$ & \\
\hline \multicolumn{5}{|l|}{$\begin{array}{l}\text { Spatial } \\
\text { relationship }\end{array}$} \\
\hline Distoangular & $1(9.1 \%)$ & $2(10.5 \%)$ & $3(10 \%)$ & \\
\hline Mesioangular & $2(18.2 \%)$ & $6(31.6 \%)$ & $8(26.7 \%)$ & 0.222 \\
\hline Vertical & $5(45.5 \%)$ & $3(15.8 \%)$ & $8(26.7 \%)$ & \\
\hline Horizontal & $3(18.2 \%)$ & $8(42.81 \%)$ & $11(33.6 \%)$ & \\
\hline \multicolumn{5}{|l|}{ No of roots } \\
\hline Single & $1(9.1 \%)$ & $5(26.3 \%)$ & $6(20 \%)$ & 0.256 \\
\hline Multiple & $10(90.9 \%)$ & $14(73.7 \%)$ & $24(80 \%)$ & \\
\hline $\begin{array}{l}\text { Duration of } \\
\text { operation in } \\
\text { minute }\end{array}$ & 40.11 & 41.38 & 40.83 & 0.89 \\
\hline
\end{tabular}

Table 2. Comparison of facial oedema among groups

\begin{tabular}{|llll} 
Time after the surgery & CTG $(n=11)$ & DXG $(n=19)$ & $p$ value \\
\hline 2nd postoperative day & $8.47 \pm 2.27 \mathrm{~mm}$ & $3.96 \pm 1.33 \mathrm{~mm}$ & $<0.001$ \\
\hline 7th postoperative day & $2.29 \pm 0.87 \mathrm{~mm}$ & $1.85 \pm 0.79 \mathrm{~mm}$ & 0.088
\end{tabular}




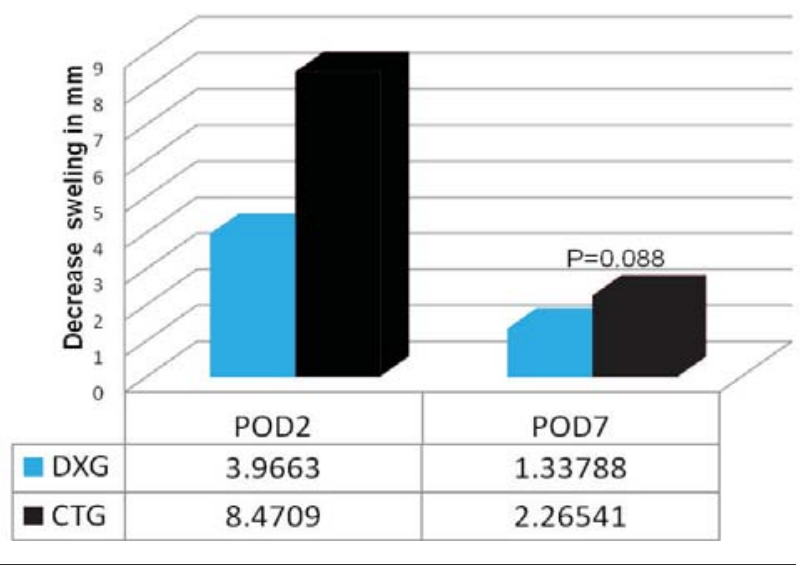

Figure 2. Effect of dexamethasone on post-operative swelling

\section{Trismus}

On the second post-operative day, there was a decrease in the IIO in both the DXG and the CTG compared to the pre-operative measurements. However, the difference between the two groups was significant $(P=0.044)$ (Table 3).

\section{Table 3. Comparison of trismus among groups}

$\begin{array}{lrrr}\begin{array}{l}\text { Time after the } \\ \text { surgery }\end{array} & \begin{array}{r}\text { CTG }(\mathrm{n}= \\ 11)\end{array} & \mathrm{DXG}(\mathrm{n}=19) & \text { p value } \\ \begin{array}{l}\text { 2nd post-operative } \\ \text { day }\end{array} & \begin{array}{r}17 \pm \\ 6.37 \mathrm{~mm}\end{array} & 13.47 \pm 5.54 \mathrm{~mm} & 0.044 \\ \begin{array}{l}\text { 7th post-operative } \\ \text { day }\end{array} & \begin{array}{l}6.72 \pm \\ 3.71 \mathrm{~mm}\end{array} & 6.63 \pm 5.54 \mathrm{~mm} & 0.318\end{array}$

On the seventh post-operative day, the reduction in mouth opening was limited in both the DXG and the CTG groups. No significant differences in the amount of IIO were noted between the two groups ( $p=0.318$ ). We observed that nearly all subjects regained preoperative IIO after TMS on Day 7 (Figure 3).

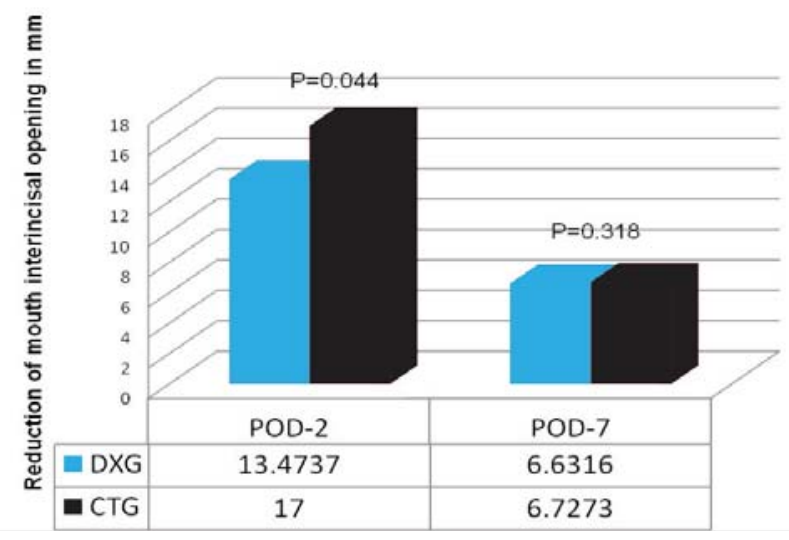

Figure 3. Effect of dexamethasone on post-operative trismus

\section{Pain and analgesia}

The exact time of the first analgesic taken after the TMS was statistically significant between the DXG and the CTG groups (Table 4).

Table 4. Analgesic taken after

\begin{tabular}{|rrrr}
\hline & DXG & CTG & $P$ value \\
\hline 1st analgesic taken TMS in min & $181.57 \pm 25.93$ & $118 \pm 17.33$ & $<0.001$ \\
\hline Number of analgesic taken & $9.21 \pm 2.66$ & $10.81 \pm 2.75$ & 0.124
\end{tabular}

The duration of analgesia was $181.58 \pm 25.93$ minutes in the DXG group while it was $118.09 \pm 17.33$ minutes in the CTG group, which was statistically significant ( $P$ $<0.0001$ ). Table 3 shows that the number of analgesics received by the subjects of the DXG group (9.21 \pm 2.64) was almost the same as that of the CTG group $(10.82 \pm 2.75)$, and that it was statistically similar between the groups ( $p=0.124)$. The VAS score for pain assessment showed progressive reduction in pain intensity from the first to the seventh post-operative day in both the groups (Figure 4). Although the total VAS scores (VAS1-7) showed a slight difference between the DXG $(5.47 \pm 2.74)$ and CTG groups $(6.09 \pm 2.02)$, it was again statistically not significant $(p=5.21)$ (Figure 4).

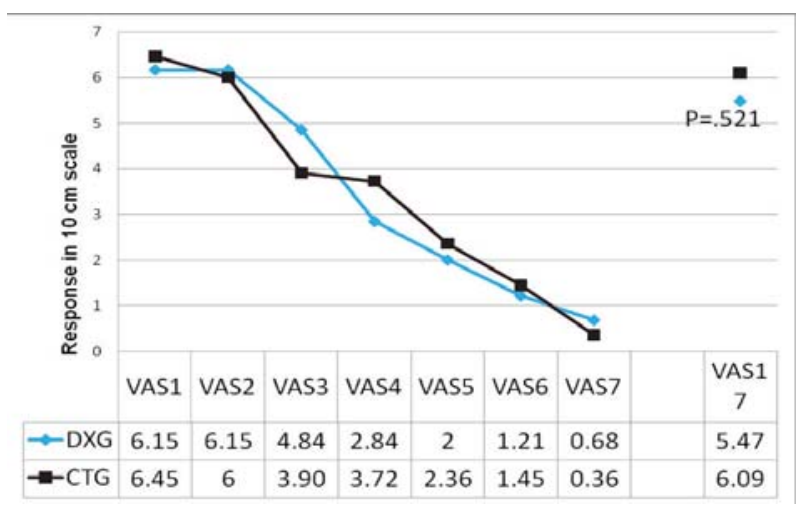

Figure 4. Comparisons of the 7 post-operative days, VAS score between the groups

\section{DISCUSSION}

Dental extraction is one of the most frequently performed surgical procedures in dental practice. But only teeth with fully-formed roots and bony impaction (usually the mandibular third molars) are more difficult to extract than those with partially-formed or no roots, requiring a more invasive surgery. It is reasonable to infer that more invasive surgery may lead to a greater inflammatory response, further justifying the use of CS only in TMS rather than in routine dental surgery ${ }^{16}$. 
Based on pathophysiologic rationale, administering CS may be considered risky by some. However, multiple studies have shown the therapeutic safety of shortterm CS exposures ${ }^{17}$. Based on pathophysiologic and reported literature, the investigators advocate the perioperative use of CS to limit predictable side effects and symptoms associated with only TMS rather than in routine dental extraction.

There are ample studies on perioperative use of CS in oral surgery, ${ }^{18,25}$ but to the best of our knowledge, only two studies have been reported on submucosal administration ${ }^{10,11}$. It has been shown in various studies that preoperative CS produces a significant result because the anti-inflammatory mediators are released immediately after the surgical trauma and CS takes 3 4 hours to act $^{26}$. However, in a typical practice setting, submucosal administering of CS three hours before surgery is usually not convenient. So we preferred submucosal injection of $8 \mathrm{mg}$ dexamethasone as local anesthesia injections just before surgical procedure, which prolong the duration of absorption leading to a maximum concentration at the site of action and a minimum systemic absorption due to the lack of the first-pass effect by the use of this route ${ }^{27}$. Hence, in this study a single dose pre-operative submucosal dexamethasone was used.

Various studies have shown a significant decrease of the post-operative swelling in patients who were given a single dose CS immediately before surgery. Markovic A et $\mathrm{al}^{28}$ reported that $\mathrm{IM} 4 \mathrm{mg}$ dexamethasone significantly decreases the post-operative swelling and trismus whereas Neupert et $\mathrm{al}^{12}$ did not find any benefit after the same administration. This may be a sub-therapeutic dosage. The effect of a submucosal injection of dexamethasone on reduction of edema on the second post-operative day has been shown in previous studies ${ }^{10,11}$. Our study showed a similar result on the second post-operative day, when maximum facial swelling was expected. However, the effect on reduction of edema on the seventh post-operative day is variable. However, in our study, we have not found any difference between the groups on the seventh post-operative day. This could be due to the fact that the swelling of the face usually resolves after a week of surgery ${ }^{4}$.Also, the half-life of dexamethasone is 36 hours and it suppresses the accumulation of leukocytes at the site of the inflammation and plasma exudation only up to the second post-operative day but not up to the seventh post operative day.

Like some previous reports do, our study showed a significant improvement in mouth opening on the second post-operative day. Graziani et $\mathrm{al}^{10}$ reported that endoalveolar applications of dexamethasone powder significantly reduce the post-operative trismus at both the second and seventh days. But surprisingly, submucosal injection of dexamethasone did not reduce trismus compared with the control group in his study. This may due to the measuring device used by different authors and individual operators may differ in the extent to which they insist on the patient opening his or her mouth widely. Ideally, mouth opening is measured by asking the patient to open the mouth slowly until pain is first felt. Mouth opening depends on the age of patient, vertical overlap of the central incisors or open bite ${ }^{14}$. Our study supports the meta-analysis by Markiewecz et al and others who found that a subject receiving CS had a significantly less trismus than the controls on the second post-operative day. On the seventh postoperative day, nearly all patients gain their pre-operative $1 \mathrm{O}^{28}$.Logically, we accepted the Peterson statement that trismus is as a result of inflammation involving several muscles of mastication and directly related to swelling ${ }^{4}$.Hence, we got significantly less trismus in the DXG group when compared with the CTG on the second post-operative day but not on the seventh postoperative day.

Although some reduction of post-operative pain generally accompanies a reduction of edema and trismus, CS alone do not seem to have a significant analgesic effect ${ }^{23,26}$. However, it has been reported that steroids reduce the number of analgesic tablets required after surgery ${ }^{6,21} \mathrm{~A}$ meta-analysis of six trials by Markiewicz et al found that CS treatment had marginally significant less pain than the control group in the early post-operative days ${ }^{28}$. We found a difference in pain perception between the groups but with no statistical significance. Dexamethasone prolongs the duration of action of local anaesthesia ${ }^{29,30}$. However, the mechanism of the prolongation of duration of block of lidocaine from dexamethasone is unclear. It has been postulated that CS causes vasoconstriction on topical application so it induces vasoconstriction in the perineurium. It is also stated that the $\mathrm{CS}$ increases tissue $\mathrm{pH}$ that results in an increase in the fraction of the drug in an unionized state, resulting in better penetration of the nerve by the drug..$^{30}$ In our study, there is a significant difference between the test and control groups with regard to the time of the first analgesic taken after the surgery which means there is a significant increase in the duration of action of the local anaesthesia. Further supported by a less VAS score and a less number of the analgesics in the first post-operative day, it is due to the long duration of action of lidocaine first, a few hour after TMS, in the presence of dexamethasone. 


\section{CONCLUSIONS}

As the TMS in our setting is usually performed under local anesthesia, there is a convenience for both the surgeon and the patient in the use of submucosal CS. Technically, the submucosal route is easier to perform, without any extra skill necessary for IV or IM, and is not dependent on patient compliance and in without noticeable systemic side effects. Our study shows that dexamethasone prolongs the duration of action of lidocaine nerve block and successfully reduces the post-operative sequelae after TMS. Hence, $8 \mathrm{mg}$ dexamethasone can be used in routine TMS to improve the post-operative quality of life of the patient, but it is not advocated in simple dental extraction.

\section{ACKNOWLEDGEMENTS}

We thank Dr Mohan Baliga and Dr Nakul Uppal of Manipal University for their guidance in the initial stages of this study. We gratefully thank $\mathrm{Mr} \mathrm{M}$. Shashidhar Kotian, Department of Community Medicine, Kasturba Medical College, Mangalore, for his help in the statistical analysis. We offer special thanks to the patients who volunteered for this study.

\section{REFERENCES}

1. Garcia GA, Sampedro GF, Rey GJ, Torreira GM. Trismus and pain after removal of impacted lower third molars. J Oral Maxillofac Surg. 1997;55:1223-6.

2. Grossi GB, Maiorana C, Garramone AR, et al. Assessing postoperative discomfort after third molar surgery: a prospective study. J Oral Maxillofac Surg. 2007;65(5):901-17.

3. Dionne RA, Gordon SM, Rowan J et al. Dexamethasone suppresses peripheral prostanoid level without analgesia in a clinical model of acute inflammation. J oral Maxillofac Surg. 2003;6:99.

4. Peterson LJ. Postoperative patient management. In: Peterson LJ, Ellis E, Hupp JR, Tucker MR, editors. Contemporary oral and maxillofacial Surgery. 4th ed. India: Mosby; 2003. P.2159.

5. Ustun, Yakup, Erdogen O, Emen E. Comparison of the effects of 2 doses of methylprednisolone on pain, swelling, and trismus after third molar surgery. Oral Surg Oral Med Oral Pathol Oral Radiol Endod. 2003;96:535-9.

6. Esen emin, Tasar ferda, Akhan, okan. Determination of the anti-inflammatory effects of methylprednisolone on the sequelae of third molar surgery. J Oral Maxillofac Surg. 1999;57:1201-6.

7. Marc L, Olivier R, François A, Sébastien R, Wajdi C, Laurent $\mathrm{G}$, et al. Comparison of methylprednisolone and ketoprofen after multiple third molar extractions: a randomized controlled study. Oral Surg Oral Med Oral Pathol Oral Radiol Endod. 2007;103:7-9.

8. Moore PA, Brar P, Smiga ER, et al. Preemptive rofecoxib and dexamethasone for prevention of pain and trismus following third molar surgery. Oral Surg Oral Med Oral Pathol Oral Radiol Endod. 2005;99(2):1-7.

9. Cemil BM, Metin G, Omer K. The effect of a single dose prednisolone with and without diclofenac on pain, trismus, and swelling after removal of mandibular third molars. J Oral Maxillofac Surg. 2006;64:1761-6.
10. Graziani F, D'Aiuto F, Arduino PG, et al: Perioperative dexamethasone reduces post-surgical sequelae of wisdom tooth removal. A split-mouth randomized double-masked clinical trial. Int J Oral Maxillofac Surg. 2006;35:241.

11. Grossi GB, Maiorana C. Effect of submucosal injection of dexamethasone on postoperative discomfort after third molar surgery: a prospective study. J oral Maxillofac Surg. 2007;65:2218.

12. Neupert EA, Lee JW, Philput CB, Gordon JR. Evaluation of dexamethasone for reduction of postsurgical sequelae of third molar removal. J Oral Maxillofac Surg. 1992;50:1177-82.

13. Schultze-Mosgau S, Schmelzeisen R, Frölich JC, Schmele H. Use of ibuprofen and methylprednisolone for the prevention of pain and swelling after removal of impacted third molars. Int J Oral Maxillofac Surg. 1997;26:380-2.

14. Okeson PJ. History and clinical examination of temporomandibular joint. Inc: Management of TMJ disorder and occlusion. 6th edition. US: Elsevier Mosby; 2008.P.21628.

15. Laetitia M, Duarteb LR, Marineb C, Lauquec D, Clay D. How patients and physicians rate patients' pain in a French emergency department using a verbally administered numerical rating scale and a visual analog scale. Acute Pain. 2008;10:31-7.

16. Hupp JR. Principles of surgery In: Peterson LJ, Ellis E, Hupp JR, Tucker MR, editors. Contemporary oral and maxillofacial Surgery. 4th ed. India: Mosby;2003:47.

17. Holte K, Kehlet H. Perioperative single-dose glucocorticoid administration: Pathophysiologic Effects and Clinical Implications. J Am Coll Surg. 2002;195(5):694-712.

18. Moore PA, et al. Preemptive rofecoxib and dexamethasone for prevention of pain and trismus following third molar surgery. Oral Surg Oral Med Oral Pathol Oral Radiol Endod. 2005;99:1-7.

19. Mark L, Richard O, Antonini F, Rousseau S et al. Comparison of methylprednisolone and ketoprofen after multiple third molar extractions: a randomized controlled study. Oral Surg Oral Med Oral Pathol Oral Radiol Endod. 2007;103:7-9. 
20. Vegas-Bustamante E, Mico Llorens J, Gargallo-Albiol J, Satorres-Nieto M, Berini-Ayte L, Gay-Escoda C. Efficacy of methylprednisolone injected into the masseter muscle following the surgical extraction of impacted lower third molars. Int J Oral Maxillofac Surg. 2008;37:260-3.

21. Gersema L, Baker K. Use of corticosteroids in oral surgery. J Oral Maxillofac Surg. 1992;50:270-7.

22. Markiewicz MR, Brady MF, Ding EL. Dodson TB. Corticosteroids reduce postoperative morbidity after third molar surgery: a systematic review and meta-analysis. J Oral Maxillofac Surg. 2008;66:1881-94.

23. Beirne OR, Hollander B. The effect of methylprednisolone on pain, trismus, and swelling after removal of third molars. Oral Surg Oral Med Oral Pathol. 1986;61(2):134-8.

24. Milles M, Desjardins PJ. Reduction of postoperative facial swelling by low-dose methylprednisolone: an experimental study. Oral Maxillofac Surg. 1993;51(9):987-91.

25. Montgomery MT, Hogg JP, Roberts DL, Redding SW. The use of glucocorticosteriod to lessen the inflammatory sequelae following third molar surgery. J Oral Maxillofac Surg. 1990;48(2):179-87.
26. Allexander RE, Throndson RT. A review of perioperative corticosteroid use in dentoalveolar surgery. Oral Surg Oral Med Oral Pathol Oral Radiol Endod. 2000;90(4):406-15.

27. George PC. Adrenocorticosteroids and adrenocortical anatagonist, In Katzug BG, editor. Basic and Clinical permacologry. 11th ed. New Delhi: Tata McGraw Hill;2009:681-97.

28. Markovic A, Todorovic LJ. Effectiveness of dexamethasone and low-power laser in minimizing oedema after third molar surgery: a clinical trial. Int J Oral Maxillofac Surg. 2007;36:226-9.

29. Yadav RK, Sah BP, Kumar P, Singh SN. Effectiveness of addition of Neostigmine or Dexamethasone to local anaesthetic in providing perioperative analgesia for brachial plexus block: A prospective, randomized, double blinded, controlled study. Kathmandu University Medical Journal. 2008;6(3):302-9.

30. Colombo G, Padera R, Langer R, Kohane DS. Prolonged duration local anesthesia with lipid-protein- sugar particles containing bupivacaine and dexamethasone. J Biomed Mater Res A. 2005;75(2):458-64. 